\title{
O PALAVRÃO: FORMAS DE ABRANDAMENTO
}

\author{
Antônio José Sandmann *
}

\section{INTRODUÇÃO}

egundo o Dicionário Aurélio, palavrão é a "palavra obscena ou 1 grosseira", podendo também ser a "palavra grande e difícil de pronunciar". No presente trabalho interessa-nos, naturalmente, o primeiro sentido, o lexicalizado ou idiomatizado, isto é, aquele em que o sufixo -āo não empresta a palavra idéia de aumento, mas de impropriedade ou inoportunidade, de ofensividade aos sentimentos do nosso interlocutor ou de nós mesmos. Da conceituação acima do Aurélio o adjetivo obsceno refere-se ao que é ofensivo ao sentimento de pudor, com destaque ao que se refere irreverentemente a sexo e atos fisiológicos da defecação e micção e partes do corpo ligadas àqueles conceitos, sendo que o adjetivo grosseiro significa mais propriamente o que é incivil, impolido, mal-educado. Exemplos de palavras obscenas teríamos em cornudo, cagāo e mijão, e de palavras grosseiras em cretino, vagabundo, caduco, lazarento!

Como se pode concluir facilmente, o palavrão se inclui num campo mais amplo da lingüistica, a saber, o do tabu lingüistico, tema freqüentemente abordado $\mathrm{em}$ lingüística, com destaque, aqui, a Lyons

* Universidade Federal do Paraná 
(423s.), Ullmann (425-35) e Mansur Guérios. Dizemos que o campo do tabu lingüistico é um campo mais amplo, porque ele compreende expressōes ou fatos que não são palavrỏes. Assim, por exemplo, temos tabus médicos: por delicadeza o médico usa eufemismos como m.h. por mal de Hansen ou lepra, c.a. de mama por cancer de mama, sendo que os próprios termos hanseníase e hanseniano podem ser vistos como eufemismos. Não se ha de dizer que mal de Hansen, lepra e leproso são palavróes, sendo que leproso pode sé-lo num xingamento: (seu) leproso! Comparando tabu com palavrão, diriamos que palavrão é mais a palavra ou expressão usada em xingamentos, contra as pessoas que nos importunam ou em vista de fatos desagradáveis, sendo que tabu lingüísuco é toda expressão tida como desagradável, porque ofensiva aos bons costumes, boas maneiras ou porque lembra fatos ou situações desagradaveis: idade mais avançada, morte, doença, p. ex.

Quando uma palavra é tabu (morrer. velho) ela pode ser substituida por um eufemismo ou palavra abrandadora (falecer. velhinho) ou, em situação inversa, por expressāo de deboche, o disfemismo: estrebuchar. caduco. No caso do palavrão, cle já é a expressão de deboche ou desaprę̧o, sendo muito comum haver formas de abrandamento. Essas formas de abrandamento, além de aspectos socioculturais, serāo enfocadas precipuamente no presente trabalho.

\section{ASPECTOS SOCIOCULTURAIS}

É interessante observar que os palavróes fazem parte de determinados campos semánticos, em outros termos, seus referentes são objetos, entidades de campos especificos do nosso universo biofisicossocial. Importante é, porém, observar que nossa atitude ou relação não é emocionalmente neutra. Impera um sentimento de sagrado - no caso da religiāo - ou de proibido - caso mais freqüente - ou ainda um sentimento qualquer de desagrado.

Como facilmente sugerem os aspectos acima destacados, deve ser possivel entrever diferenças culturais entre comunidades lingüisticas no que diz respeito ao uso do palavrāo. Não fiz um estudo voltado para essas diferenças étnico-culturais, mas a observação baseada em minha experiència de vida me permite afirmar que o alemão xinga muito com palavrões ligados a falta de higiene ou sujeira: Schwein "porco", San "porca", Scheise "merda", sendo que falante nativo de alemāo me testemunhou que xin- 
gamento especialmente forte é chamar alguém de grosses Dreckschwein "grande porco sujo".

No italiano chamam a atençāo palavrões ligados à religião: porco dio, porca madonna, abrandados, muitas vezes, como veremos na seção seguinte, para porco sio e porca madoi. Já no português parecem ganhar destaque xingamentos ligados à sexualidade, especialmente o que se chama os desvios morais da sexualidade: filho da puta, veado, galinha. Queremos deixar claro, porém, que não fizemos estudo mais dedicado com o objetivo de levantar estatisticamente diferenças étnico-culturais, o que não deixa de ser um desafio interessante, pois nos permitiria obter possiveis contrastes entre comunidades lingüistica e culturalmente bastante diversas, p. ex., o japonès, o coreano, o chinês, os indígenas, os nativos africanos, curopeus do Norte e do Sul.

Focalizando apenas o palavrāo tal qual ele é corrente entre nós, podemos apontar alguns campos semânticos nos quais ele se nutre com destaque. Referindo-se ao homem, ser humano do sexo masculino, ganham acento os palavrões que enfocam a sexualidade passiva (bicha, veado) e o ser vitima de infidelidade (corno, chifrudo), enquanto a mulher é estigmatizada mais pela prostituiçăo (puta, galinha, fêmea), sendo de destacar o aspecto cultural de que se fêmea é negativo para mulher, macho e machão não são para o homem.

Outros campos que se destacam como fontes de palavrỏes: a religião (desgraçado, diabo); a idade, mais baixa (fedelho, frango) ou mais avançada (coroa, velharia, caduco); a falta de higiene (ponco); a defecação e a miç̧ão (cugāo, mijāo); a atribuição dos nomes das partes do corpo animal às partes análogas do ser humano (pata, juba, crina, focinho), bem como dos nomes dos animais ao homem (cavalo, poreo, elefante). Fatos históricos também podem dar origem a palavras de xingamento: judeu, nazista, fascista e até comunista, merecendo destaque que pode haver preconceito.

Parece-me importante também chamar a atenção para o fato de haver graus de agressividade e rejeição no palavrão. Assim há um indubitável crescimento em: Fica brabo, danado, puto., ou Selı medroso, mijāo, cagão!

Merece, finalmente, destaque o uso de sufixos que se prestam à expressão da pejoratividade: -óide (fascistóide, comunistóide, ideologóide); -āo (resmungão, pidāo, do popular pidir); -ento (molambento, caspento) etc. A propósito importa realçar que à idéia negativa que o sufixo empresta à palavra muitas vezes vem se somar a negatividade da base (fascistóide), outras vezes é mais do sufixo (ideologóide), não se devendo esquecer que a 
negatividade atribuida à base pode ser questão de atitude pessoal ou até de preconceito (comunistóide).

\section{FORMAS DE ABRANDAMENTO}

Mansur Guérios (11), referindo-se as formas de abrandamento do tabu lingüistico, diz: "O recurso empregado são meios indiretos e meios diretos dissimulados, isto $\dot{e}$, substitutos que velem de qualquer modo o ser sagrado-proibido." Desses meios de dissimulação poderíamos afirmar que eles são formas de "dizer, não dizendo" ou de "não dizer, dizendo", eis que, na verdade, ofalante diz de forma velada, mas diz. Quando personagem de Dalton Trevisan, em "a Polaquinha" (p. 63, Rio de Janeiro: Record, 7" edição), diz desgracido ao invés de desgraçado, há apenas um abrandamento de expressão de fundo religioso que diz que alguém está condenado, sem a graça de Deus.

Damos, a seguir, destaque às principais formas de abrandamento com que deparamos em nossa constante pesquisa lexical, que inclui, sem dúvida, as formas de velar o que é proibido e rejeitado, por ser obsceno ou por sua agressividade, formas de abrandamento comumente chamadas eufemismos:

Abreviação

Como formas de abreviação destacam-se a soletraçāo dos fonemas iniciais: (estar na) eme, pap (Folha, de 29.12.90, p.A-2: "Com tanta sigla, não espanta que a mais usada nas ruas seja uma tal de PQP."), (estar) pé (da $\checkmark i d a), c \dot{e}-d \dot{e}, c \dot{e}-d e^{-}-f e, b e^{i}-u n d a$; o uso apenas das silabas iniciais: sifo, mifo, paca ou praca (Folha, de 1.10.87, p. A-50: "Cometo erros praca."), csspone, csmene, pi; abreviaçōes diversas: demo. Vi tomá...' O seu...!

Modificaçāo de fonema(s)

Substitui-se fonema, às vezes mais de um, do palavräo: (sempre a) lesma lerda. poxa, puxa, diacho, desgracido, desgramado, desgranido, do italiano porco sio por porco dio, sio can por dio can.

Substituiçāo de palavras

Essias substituições de palavra de frase ou sintagma podem ser de caráter geral ou não-especifico: filho da mäe, estudou para can alho (da Folha, 5.11.88, E-10: "Fizeram um escandalo do carvalho com a NBC."), dar como respectivo na trave vá tomar banho! As substituiçöes de palavras podem ser de carater mais especilico, envolvendo a pronominalização: mandar para aquele lugar. fomar naquele lugar. só persia naquilo, ou a trocai 
por palavra-ônibus como coisa (Tribuna do Paraná, de 19.07.88, p.1: "Castrado a dentadas. Antenor Cordeiro perdeu um pedaço da 'coisa" ao brigar com três.")

Paráfrase e circunlóquio

A paráfrase é a expressão de sinonímia mais presa à da expressão a ser evitada do que a do circunlóquio. Exemplos de paráfrase: as partes de baixo, as partes pudendas, fazer mal a. Exemplos de circunlóquio: tirar água do joelho, botar o ovo matinal.

\section{ASPECTOS PRAGMÁTICOS}

No final da seção 2 foi chamada atenção para o fato de nem todos os palavrões despertarem o mesmo grau de rejcição ou conterem o mesmo grau de agressividade. Aqui alertamos para o fato de as pessoas não reagirem da mesma forma ao palavrāo e de fazerem uso dele em graus diversos de freqüência, sendo de destacar diferenças entre os sexos, entre as idades e niveis sociais, p. ex. Relativamente à idade posso reportar que nos elevadores da Faculdade tenho ouvido grupos de jovens, formados por pessoas de ambos os sexos, usarem sem cerimônia de palavras ou expressōes como fodeu-se, puta merda, porra,testemunho de mudança de gerações como do relacionamento entre os sexos. Um jovem dizia a sua companheira: "Dá um tempo né, bem! Puta que pariu!" Testemunho de diferenças sociais teríamos no exemplo seguinte, $\mathrm{cm}$ que uma servente dizia às outras: "Faz as cagadas dela, depois fica se batendo."

O que temos presenciado com freqüência é o que chamariamos de "jogo de faz-de-conta", isto é, o palavrão é dito mas não é para valer, como no seguinte fato em que um jovem gritou para outro, do outro lado da rua: "Ô baixinho filho da puta!", atravessaram a rua e se abraçaram. Aliás, não é raro assistir a esse jogo de cena em que jovens do sexo masculino se estapeiam, escoiceiam, e trocam "amabilidades" lingüísticas, chegando as vezes até a procurarem atingir os órgãos genitais ou lá "onde-as-costamudam-de-nome". 


\title{
CONCLUSÃO
}

Independentemente de aspectos de envolvimento ético ou do que diz respeito às boas maneiras e à civilidade, o palavrão e o campo maior do tabu lingüístico pelo qual ele é abrangido são causa interessante de criação lingüística, de recursos responsáveis por todo um jogo de encobrir, de fazer de conta, de "não dizer, dizendo" ou de "dizer, não dizendo". Conclusōes sobre diferenças culturais e sociais não são difíceis de tirar, sendo que corolários sobre diferenças étnico-culturais no uso do palavrão exigiriam pesquisa baseada em corpus mais amplo e mais especifico.

\section{RESUMO}

Abordam-se aqui aspectos lingüisticos e socioculturais do palavrão em seu significado de "palavra obscena ou grosseira" (V. Aurélio). Sob o enfoque lingüistico, ganham destaque as várias formas de abrandamento, os eufemismos.

\begin{abstract}
The aim of this paner is to examine the linguistic and sociocultural aspects of the swear-word in its meaning as both "an obscene and gross word" (cf. Aurélio). Under a linguistic point of view, we focus the various forms of softening, the euphemisms.
\end{abstract}

\section{REFERÊNCIAS BIBLIOGRÁFICAS}

FERREIRA, A.B. de H. Novo Dicionário da Lingua Portuguesa. Rio de Janeiro: Nova Fronteira. 1986 (Referido no texto como Aurélio). JORNAL Folha de Sāo Paulo (referido no texto como Folha). JOTA, Z. dos Santos. Dicionário de Lingüistica. Rio de Janeiro: Presença, 1976. LYONS, J. Introduction to Theoretical Linguistics. Cambridge: University Press, 1968. MANSUR GUERIOS, R.F. Tabus Lingüisticos. São Paulo: Companhia Editora Nacional, 1979. ULLMANN. S. Semántica: uma Introduçăo à Ciència do Significado. Lisboa: Fundaçāo

Calouste Gulbenkian. 1964. 